\title{
Comparative Study of Copper Adsorptivity and Selectivity toward Zeolites
}

\author{
Ponyadira Kabwadza-Corner*, Moses Wazingwa Munthali, Erni Johan, Naoto Matsue \\ Laboratory of Applied Chemistry for Environmental Industry, Faculty of Agriculture, Ehime University, \\ Matsuyama, Japan \\ Email: ponya83@yahoo.co.uk
}

Received 17 March 2014; revised 25 April 2014; accepted 3 May 2014

Copyright (C) 2014 by authors and Scientific Research Publishing Inc.

This work is licensed under the Creative Commons Attribution International License (CC BY).

http://creativecommons.org/licenses/by/4.0/

(c) (i) Open Access

\begin{abstract}
The objectives of the study were to find the type and species of zeolite which gives optimum adsorption of copper, provide an explanation of the mechanism involved in the adsorption process and establish the selectivity sequence among zeolites. Adsorption of $\mathrm{Cu}$ onto zeolites and montmorillonite as a reference was conducted at an initial $\mathrm{Cu}$ concentration range of $0-0.60 \mathrm{mM}$ in the presence of $100 \mathrm{mM} \mathrm{NH}_{4} \mathrm{NO}_{3}$ at initial $\mathrm{pH}$ of 5 . Langmuir and Freundlich models were used in analyzing the equilibrium data and a selectivity sequence derived from the Langmuir calculation was A4 $>$ faujasite $X>$ modernite $>$ Na-P1 $\approx$ montmorillonite $\approx$ faujasite $Y>$ clinoptilolite. Zeolites A4 and faujasite $X$ had high adsorptive capacities of $1429 \mathrm{mmol} \cdot \mathrm{kg}^{-1}$ and $909 \mathrm{mmol} \cdot \mathrm{kg}^{-1}$, respectively. Zeolite A4 has the highest CEC among all the samples $\left(6150 \mathrm{mmol} \cdot \mathrm{kg}^{-1}\right)$, and the adsorption capacity of $\mathrm{Cu}$ was largely influenced by the CEC of the samples. The adsorption mechanism was based on the exchange of $\mathrm{Cu}$ from solution with mostly $\mathrm{Na}$ which was the main exchangeable cation available. These results are important in selecting the most effective and suitable adsorbent for $\mathrm{Cu}$ removal from polluted environments.
\end{abstract}

\section{Keywords}

Heavy Metals, Cu Adsorption, Selectivity, Precipitation, Cation Exchange

\section{Introduction}

Heavy metals, such as $\mathrm{Cu}, \mathrm{Cd}, \mathrm{Pb}$ and $\mathrm{Zn}$, are toxic to human beings and other living organisms if their concentrations exceed certain values. Copper is heavily used in industries for such uses as plating, mining and smelting, brass manufacture, electroplating, petroleum refining and Cu-based agrichemicals mining. The use of heavy

"Corresponding author. 
metals in these industries produces a lot of wastewater and sludge containing $\mathrm{Cu}$ in various concentrations. These have negative effects on water and the environment in general [1]. Copper may also be found as a contaminant in various foods, especially in shellfish, liver, mushrooms and nuts [2]. It has been reported that excessive intake of $\mathrm{Cu}$ by humans may lead to severe mucosal irritation, hepatic and renal damage, widespread capillary damage and central nervous system problems [3]. The World Health Organization recommended a maximum acceptable concentration of $\mathrm{Cu}$ in drinking water of $1.5 \mathrm{mg} \cdot \mathrm{L}^{-1}$ [4]. Therefore, the concentration of this metal must be reduced to a level that satisfies national and international environmental best practices (regulations) for various water bodies.

The most commonly used techniques for removing $\mathrm{Cu}$ ions from aqueous solutions include oxidation, reduction, precipitation, membrane filtration, biological process, ion exchange and adsorption. Adsorption of heavy metals on various materials has been conducted by researchers with the objective of finding efficient and cost effective means of removing heavy metals. Many researchers have been investigating low-cost adsorbents for heavy metal removal such as sawdust [3], rice husks [5], sago waste [6], red pepper seeds [7], treated Indian barks [8], teak leaves powder [9], saltbush leaves [10], groundnut shells [11], tree fern [12], chitosan beads [13] and zeolites [14] [15].

Zeolites, with their permanent negative charges as well as the interconnection of channels and cages that run through their secondary framework structure, are effective adsorbents for positively charged pollutants such as heavy metals [16]. Zeolites have a three-dimensional structure which constitutes of ( $\mathrm{Si}, \mathrm{Al}) \mathrm{O}_{4}$ tetrahedra connected by all their oxygen vertices forming channels where exchangeable cations counterbalance the negative charge generated from isomorphous substitution. They have specific properties such as large surface area, high cation exchange capacity (CEC) and surface acidity so they are applied to many fields of industry as adsorbents, molecular sieves, ion exchangers and catalysts.

Zeolites can be found in nature (natural zeolites); they can be synthesized from chemical reagents (synthetic zeolites) or can be prepared from industrial by-products such as coal fly ash (artificial zeolites). In this study, zeolites A4, faujasite X, faujasite Y, Na-P1, clinoptilolite and modernite were used with the objective of removing $\mathrm{Cu}$ from an aqueous solution through adsorption and establishing a selectivity sequence. At the same time, in order to compare the selectivity between zeolites and other naturally existing minerals, montmorillonite was also used. Montmorillonite is a type of clay mineral that has been used as an adsorbent for a long time. It is a 2:1 type layer silicate mineral characterized by its interlayer space and external surface which are particularly suitable for reactions such as adsorption of heavy metal ions and organic compounds.

This study therefore aimed at finding the zeolite species that would give optimum adsorption results and describing the mechanism of adsorption for the particular zeolite. It also aimed at establishing a selectivity sequence of $\mathrm{Cu}$ toward these zeolites and montmorillonite. Although there are many zeolite species, not all of them are available and suitable for optimum adsorption of heavy metals such as $\mathrm{Cu}$ hence the need for research into which zeolite species can best optimize adsorption of $\mathrm{Cu}$. Among the studies on $\mathrm{Cu}$ adsorption that have been conducted, the main focus has been on finding a single adsorbent that can adsorb Cu either from a mixture of heavy metals or a homogenous solution [17]-[20]. These studies have not focused on the use of various adsorbents for adsorption of a single heavy metal in order to determine selectivity among adsorbents hence the current study was conducted to obtain the adsorbent which has high selectivity toward $\mathrm{Cu}$ as well as high adsorption.

\section{Materials and Methods}

\subsection{Zeolite Samples}

The choice of zeolite samples for this experiment based on the variations in their CEC, the difference in their pore structures as well as their availability. Commercially available zeolite A4, faujasite $\mathrm{X}$, faujasite $\mathrm{Y}$, modernite, clinoptilolite and montmorillonite were used while Na-P1 was synthesized in this study. Zeolites A4 and faujasite X were supplied by Wako Pure Chemicals Industries Japan, faujasite Y was supplied by Tosoh Company, Japan, natural modernite from Fukushima Prefecture in Japan, natural clinoptilolite from Shimane Prefecture in Japan and natural montmorillonite was supplied by Japan Clay Science society. The above samples were used with $\mathrm{Na}^{+}$saturation in order to have $\mathrm{Na}^{+}$as the uniform exchangeable cation. Na-P1 was synthesized by adding a diluted solution of $\mathrm{NaOH}$ to a specified amount of $\mathrm{NaAlO}_{2}$. After a few minutes of stirring, $\mathrm{NaSiO}_{4}$ was added dropwise. This mixture was heated on a hot plate for $24 \mathrm{~h}$ and thereafter, the samples were washed 3 
times with $100 \mathrm{~mL}$ water and dried at $40^{\circ} \mathrm{C}$ for $24 \mathrm{~h}$.

\subsection{Sample Characterization}

Samples were characterized by powder X-ray diffraction (XRD) using a Rigaku Ultima IV X-ray Powder X-ray Diffractometer with Cu-K $\alpha$ radiation generated at $40 \mathrm{kV}$ and $40 \mathrm{~mA}$, between $3^{\circ}-60^{\circ}$ of $2 \theta$ angles with a sampling width of $0.02^{\circ}$ and a scanning rate of $2^{\circ} \min ^{-1}$. The amounts of $\mathrm{Si}$ and $\mathrm{Al}$ were measured by X-ray fluorescence (XRF) using a Rigaku RIX 2100 XRF. It was operated at a tube voltage of $30 \mathrm{kV}$ and a tube current of $100 \mathrm{~mA}$. Cation exchange capacity (CEC) was measured by initial saturation of samples with $1 \mathrm{M} \mathrm{KCl}$ solution. The $\mathrm{K}^{+}$saturated samples were washed with $1 \mathrm{M} \mathrm{NH}_{4} \mathrm{Cl}$ solution in order to remove the exchangeable $\mathrm{K}^{+}$ions. The amount of $\mathrm{K}^{+}$in the supernatant was measured using atomic absorption spectrophotometer (AAS, Hitachi Z-5000) and the CEC was calculated.

\subsection{Adsorption Experiments}

Adsorption of $\mathrm{Cu}$ was conducted using $50 \mathrm{~mL}$ of $\mathrm{Cu}\left(\mathrm{NO}_{3}\right)_{2}$ solution with initial concentrations of $0,0.05,0.10$, $0.15,0.20,0.30,0.45,0.60 \mathrm{mM}$ and $0.01 \mathrm{~g}$ of $\mathrm{Na}^{+}$saturated zeolite and montmorillonite samples. The experiments were conducted in the presence of $100 \mathrm{mM} \mathrm{NH}_{4} \mathrm{NO}_{3}$ and a constant initial $\mathrm{pH}$ of 5: $\mathrm{pH}$ adjustment was done using $1 \mathrm{mM} \mathrm{HNO}$ by adding drops of $\mathrm{HNO}_{3}$ to a mixture of $\mathrm{Cu}\left(\mathrm{NO}_{3}\right)_{2}$ and $\mathrm{NH}_{4} \mathrm{NO}_{3}$ in concentrations that have been mentioned earlier. The coexistent $\mathrm{NH}_{4} \mathrm{NO}_{3}$ represents coexisting ions in the polluted waters. Experiments were conducted at room temperature using centrifuge bottles with aluminium foil covering in order to prevent precipitation due to sunlight. Shaking was done for $1 \mathrm{~h}$ which was experimentally pre-determined to be sufficient for adsorption equilibrium to be reached. After shaking, the samples were centrifuged at $1600 \mathrm{~g}$ for 10 min then $\mathrm{pH}$ of the supernatant was measured. Finally, the concentration of $\mathrm{Cu}$ in the supernatant was measured by AAS. The amount of adsorption of $\mathrm{Cu}$ was calculated from the difference between initial and final $\mathrm{Cu}$ concentrations.

\section{Results and Discussion}

\subsection{Characterisation of Samples}

The samples were analyzed before commencement of the adsorption experiments: CEC measurement, Si/Al ratio determination, and XRD analysis. Table 1 is an illustration of the CEC and $\mathrm{Si} / \mathrm{Al}$ ratio of the samples. Zeolite A4 was the sample with the highest CEC of $6150 \mathrm{mmol} \cdot \mathrm{kg}^{-1}$ followed by the rest of the samples.

Figure 1 shows the XRD patterns of the samples. The diffraction peaks for zeolites A4, faujasite X, faujasite $\mathrm{Y}$ and Na-P1 all correspond to the typical structures of the aforementioned samples that have been observed in literature [21]. Clinoptilolite and modernite both displayed patterns that correspond to those indicated by Dixon and Weed [22]. With montmorillonite, the XRD patters revealed the three main peaks of Na-montmorillonite. The pattern itself corresponded to that reported by Mering and Brindley [23].

\subsection{Copper Adsorption Isotherms}

Preliminary experiments confirmed that adsorption equilibrium was reached within $1 \mathrm{~h}$ of shaking. At the same time, it was revealed through these experiments that an increase in $\mathrm{pH}$ to $>6.5$ resulted into the precipitation of

Table 1. CEC and Si/Al ratio of the samples.

\begin{tabular}{ccc}
\hline Sample & CEC $\left(\mathbf{m m o l} \cdot \mathbf{~ k g}^{-\mathbf{1}}\right)$ & Si/Al $\mathbf{~ r a t i o ~}$ \\
\hline A4 & 6150 & 1.00 \\
Faujasite X & 5560 & 1.24 \\
Faujasite Y & 3470 & 2.66 \\
Na-P1 & 4500 & 1.67 \\
Modernite & 2457 & 4.88 \\
Montmorillonite & 1200 & - \\
Clinoptilolite & 2112 & 5.04 \\
\hline
\end{tabular}




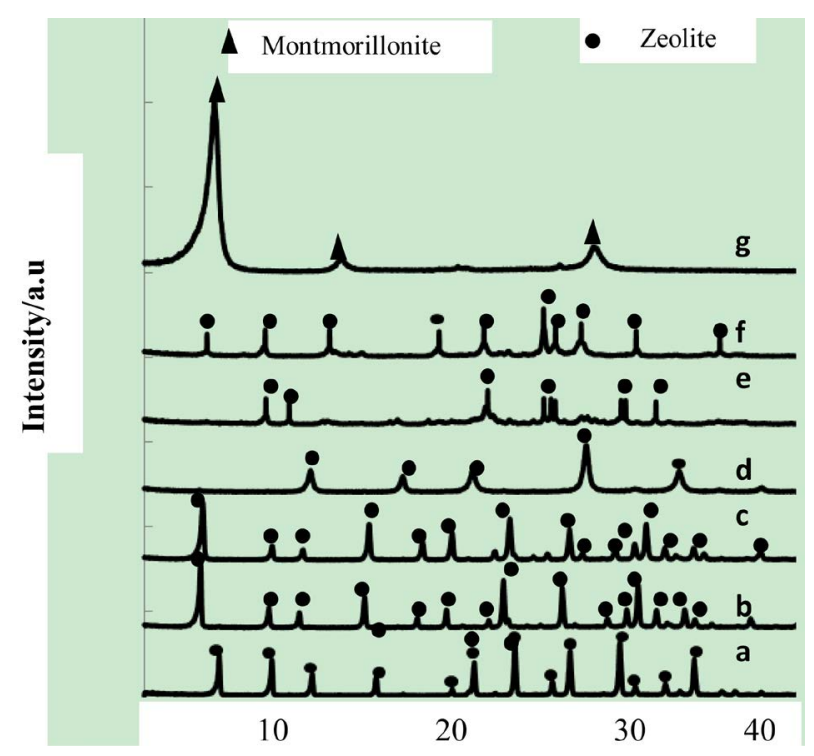

Figure 1. RD patterns of the samples. a: A4, b: faujasite X, C: faujasite Y, d: Na-P1, e: clinoptilolite, f: modernite and g: montmorillonite.

$\mathrm{Cu}$ hence experiments were conducted at an initial $\mathrm{pH}$ of 5 to avoid precipitation and to maintain the equilibrium $\mathrm{pH}$ to $<6.5$.

The results were analyzed using Langmuir and Freundlich isotherm analysis methods. The analysis of the isotherm data is important to develop an equation which accurately represents the results and which could be used for design purposes. There are essentially three stages in the adsorption process by porous adsorbents [24]: 1) solute transfer from the bulk solution to the external surface of the sorbent through a liquid boundary layer (film resistance); 2) solute transfer from the sorbent surface to the intra particle active sites (intra particle resistance); and 3) interactions of the solute with the available sites on both the external and internal surfaces of the sorbent (reaction resistance). One or more of the above-mentioned stages may control the rate at which the solute is adsorbed and the amount of solute that is adsorbed onto the sorbent. In this study, since various zeolites with different properties were used, most of the aforementioned factors may have played a role in the adsorptive selectivity of the samples. Figure 2 shows the adsorption isotherms of $\mathrm{Cu}$ on the previously mentioned samples.

The adsorptive capacity of the samples was analyzed using Langmuir analysis method. The Langmuir linear equation used was:

$$
\frac{C}{X}=\frac{1}{X_{m} K}+\frac{C}{X_{m}}
$$

where $C$ is the equilibrium concentration $\left(\mathrm{mmol} \cdot \mathrm{L}^{-1}\right), X$ the amount adsorbed $\left(\mathrm{mmol} \cdot \mathrm{kg}^{-1}\right), X_{m}$ the maximum adsorption (mmol $\cdot \mathrm{kg}^{-1}$ ) and $K$ a constant related to binding energy $\left(\mathrm{L} \cdot \mathrm{mmol}^{-1}\right)$. A plot of $C / X$ against $C$ resulted into a straight line for most of the samples with A4 having the highest correlation efficiency $\left(\mathrm{R}^{2}\right)=0.9943$. The values of $X_{m}, K$ and $\mathrm{R}^{2}$ determined by Langmuir analysis are tabulated in Table 2 . The selectivity sequence thus determined was $\mathrm{A} 4>$ faujasite $\mathrm{X}>$ modernite $>\mathrm{Na}-\mathrm{P} 1 \approx$ montmorillonite $\approx$ faujasite $\mathrm{Y}>$ clinoptilolite. The Freundlich linear equation was also used for analyzing the adsorption data. The linear equation used was:

$$
\log X=\log K+1 / n \log C
$$

where $X=$ amount of substance adsorbed $\left(\mathrm{mmol} \cdot \mathrm{kg}^{-1}\right), C=$ Equilibrium concentration $\left(\mathrm{mmol} \cdot \mathrm{L}^{-1}\right), K=$ constant related to both the strength and amount of adsorption while $1 / n=$ the intensity of adsorption. The magnitude of the exponent $1 / n$ gives an indication of the favorability of adsorption. Values of $n$, where $n>1$ represent favorable adsorption condition. The values of $K, n$ and $\mathrm{R}^{2}$ calculated by the linear form of Freundlich model are illustrated in Table 2. Zeolite A4 had the highest $K$ and $n$ values as was the case with Langmuir analysis.

In general, $\mathrm{Cu}$ had the highest selectivity toward zeolite A4 which had the highest adsorptive capacity. The adsorption isotherm for A4 was very steep in the lower concentration range compared to the other samples. This 


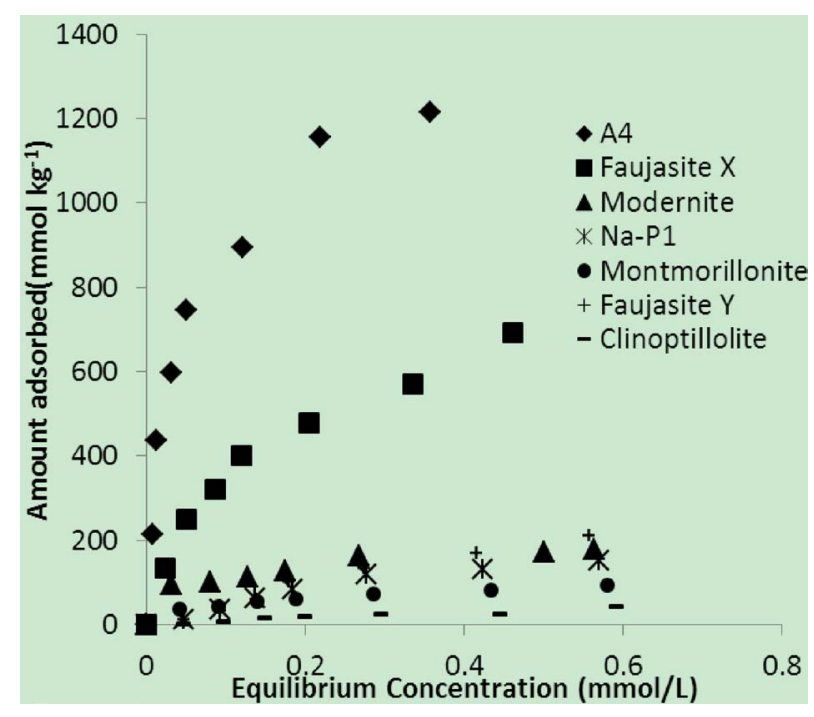

Figure 2. Copper adsorption isotherms on zeolites A4, faujasite $\mathrm{X}$, modernite, Na-P1, montmorillonite, faujasite $\mathrm{Y}$ and clinoptilolite. $0.01 \mathrm{~g}$ of each sample were mixed with $50 \mathrm{~mL}$ of $0-1.2$ $\mathrm{mmol} \cdot \mathrm{L}^{-1} \mathrm{CuNO}_{3}$ in the presence of $100 \mathrm{mM} \mathrm{NH} \mathrm{NO}_{3}$, and shaken for $1 \mathrm{~h}$. Initial $\mathrm{pH}$ was 5 for all experiments.

Table 2. Langmuir and Freundlich parameters of $\mathrm{Cu}$ adsorption.

\begin{tabular}{ccccccc}
\hline \multirow{2}{*}{ Sample } & \multicolumn{3}{c}{ Langmuir model } & \multicolumn{3}{c}{ Frendaulich model } \\
\cline { 2 - 7 } & $\boldsymbol{X}_{\boldsymbol{m}}$ & $\boldsymbol{K}$ & $\mathbf{R}^{2}$ & $\boldsymbol{K}$ & $\boldsymbol{n}$ & $\mathbf{R}^{\mathbf{2}}$ \\
A4 & 1429 & 0.0200 & 0.99 & 229 & 3.44 & 0.98 \\
Faujasite X & 909 & 0.0060 & 0.98 & 49 & 2.37 & 0.99 \\
Faujasite Y & $(667)$ & $(0.0008)$ & $(0.60)$ & 1.0 & 1.22 & 0.94 \\
Na-P1 & 250 & 0.0027 & 0.96 & 4.0 & 1.70 & 0.94 \\
Modernite & 192 & 0.0110 & 0.92 & 28 & 3.40 & 0.92 \\
Montmorillonite & 116 & 0.0057 & 0.99 & 9.0 & 2.74 & 1.00 \\
Clinoptilolite & $(74)$ & $(0.0016)$ & $(0.55)$ & 0.57 & 1.54 & 0.88 \\
\hline
\end{tabular}

resulted in A4 having the highest Langmuir $K$ constant compared to all other samples. The steep nature of the isotherm further indicated that $\mathrm{Cu}$ was more strongly attached to zeolite A4 than the rest of the samples, indicating that $\mathrm{A} 4$ would be used efficiently for the adsorption of $\mathrm{Cu}$ in nature at low concentrations. This was followed by faujasite $X$ and the rest of the samples. On the contrary, clinoptilolite which had the lowest $X_{m}$ also had an isotherm that was almost flat in the lower concentration range, implying low adsorption and a weaker binding strength of $\mathrm{Cu}$ to the adsorbent. The Langmuir $K$ constant which relates to binding energy of the samples however did not exactly follow a similar order to that of adsorption. This meant that although $\mathrm{Cu}$ was highly adsorbed onto some samples in terms of quantity, the bond that was formed between $\mathrm{Cu}$ and available sites of the adsorbent was not very strong.

Modernite was one of the samples whose adsorptive capacity was comparatively lower than all the synthetic zeolites but the Langmuir $\mathrm{K}$ constant was high, indicating that $\mathrm{Cu}$ was strongly adhered to this sample. In other words, the force of attraction between the adsorbent and adsorbate was very strong even though the amount of adsorption was low.

In a related study, Hui et al. [25] experimented on the adsorption and selectivity sequence of mixed metal ions $\mathrm{Co}^{2+}, \mathrm{Cr}^{3+}, \mathrm{Cu}^{2+}, \mathrm{Zn}^{2+}$ and $\mathrm{Ni}^{2+}$ toward zeolite A4 in a batch experiment system. Results indicated a selectivity sequence of $\mathrm{Cu}^{2+}>\mathrm{Cr}^{3+}>\mathrm{Zn}^{2+}>\mathrm{Co}^{2+}>\mathrm{Ni}^{2+}$. The amount of $\mathrm{Cu}$ adsorption on A4 however was around 794 $\mathrm{mmol} \cdot \mathrm{kg}^{-1}$, which is almost half of the amount of adsorption of $1429 \mathrm{mmol} \cdot \mathrm{kg}^{-1}$ in current experiment. Factors such as crystal structure of zeolite 4A, free energy of hydration and hydrated radii of the metal ions as well as the CEC of the adsorbent may be responsible for the observed selectivity in this study. Zeolites, in general, are 
weakly acidic in nature and therefore sodium form exchangers are selective for protons ( $\mathrm{RNa}+\mathrm{H}_{2} \mathrm{O} \Leftrightarrow \mathrm{RH}+$ $\mathrm{Na}^{+}+\mathrm{OH}^{-}$). This leads to high $\mathrm{pH}$ values when the exchanger is equilibrated with a relatively dilute electrolyte solution [26], making feasible the metal hydroxide precipitation. The crystal structure of zeolite 4A contains large cages having a near spherical shape and free diameter of $11.4 \AA$. Each of these cages is connected with six neighboring cages via eight-membered rings (8-MR) having a crystallographic diameter of $4.1 \AA$. The effective pore width of zeolite $4 \mathrm{~A}$ is $4 \AA$. A common factor preventing a group of metal ions from being adsorbed by zeolite $4 \mathrm{~A}$ is the size of the hydrated ion. If the hydrated ion size is greater than that of the pore, the species may be excluded or some of the waters of hydration must be stripped from the solvated ions to enable them to enter the pores of the zeolite. Copper has a hydrated radius of $4.19 \AA$ [27] an unhydrated radius of $0.82 \AA$ and a free energy of hydration of $-498.7 \mathrm{kcal} \mathrm{g}^{-1}$-ion [25]. Although the hydration radius was as such, there is high possibility that some amount of $\mathrm{Cu}$ penetrated inside the pore spaces of zeolite A4.

In related studies montmorillonite in $\mathrm{Na}$ form adsorbed $47.8 \mathrm{mmol} \cdot \mathrm{kg}^{-1}$ of $\mathrm{Cu}$ [17]. This adsorptive capacity was lower than that of $\mathrm{Na}$ montmorillonite in the current experiment which was $116 \mathrm{mmol} \cdot \mathrm{kg}^{-1}$. This was mainly because the experiment by Abollino et al. [17] was conducted at varying $\mathrm{pH}$ range of $2.5-8.0$ and in the presence of ligands, forming complexes of different stabilities with the metals of interest since the study included other metals like $\mathrm{Cd}, \mathrm{Cr}, \mathrm{Cu}, \mathrm{Mn}, \mathrm{Ni}, \mathrm{Pb}$ and $\mathrm{Zn}$. The $\mathrm{pH}$ variations influenced to a higher extent the concentrations of $\mathrm{Cu}, \mathrm{Pb}$ and $\mathrm{Cd}$ in the effluent used in the experiment. Moreover the results suggested that complex formation hindered the adsorption of the metals on the clay, hence the lower adsorptive capacity than the current study. Clinoptilolite and Fe modified clinoptilolite on the other hand had adsorptive capacities of 214 $\mathrm{mmol} \cdot \mathrm{kg}^{-1}$ and $590 \mathrm{mmol} \cdot \mathrm{kg}^{-1}$ [28] for Cu which was higher than the $74 \mathrm{mmol} \cdot \mathrm{kg}^{-1}$ recorded in current study. The main factors that contributed to different adsorption capacities of the two solids (clinoptilolite and Fe modified clinoptilolite) were the new surface species and negative charge of the clinoptilolite-Fe system. In addition, it was found that for most of the samples the clinoptilolite-Fe system released lower concentrations of counterbalance cations ( $\mathrm{Ca}, \mathrm{Mg}$ and $\mathrm{Na}$ ) and higher concentrations of $\mathrm{K}$ than clinoptilolite, while the dissolution of $\mathrm{Si} / \mathrm{Al}$ was limited. These factors coupled with the difference in the solid: solution ratio may have contributed to the difference in the adsorptive capacities of this experiment and the experiment reported in this paper.

Faujasite $\mathrm{X}$, faujasite $\mathrm{Y}, \mathrm{N}$ a-P1, clinoptilolite and modernite on the other hand have pore sizes of $7.4 \AA$ [27], $7.3 \AA \& 4.8 \AA$ [29], 4.5 - $6 \AA$ [30] and $4.2 \AA$ [31], respectively. According to the effective pore sizes of zeolites $\mathrm{A}, \mathrm{X}$ and $\mathrm{Y}$, the amount of metal ions adsorbed on zeolite $\mathrm{X}$ and $\mathrm{Y}$ should exhibit more than zeolite $\mathrm{A}$. However, the effective pore size of zeolites $\mathrm{A}, \mathrm{X}$ and $\mathrm{Y}$ do not explain clearly, the high adsorption capacity of the synthetic zeolite A. It is therefore thought that the main mechanism involved in the sorption of $\mathrm{Cu}$ in this case is based on cation exchange capacity of zeolites or its charge density. It was observed that the order of selectivity of adsorption was closely linked to the cation exchange capacities of the samples. The sample with the highest CEC also had the highest adsorptive capacity and vice versa. The difference in the amounts of Cu adsorption between faujasite $\mathrm{X}$ and faujasite $\mathrm{Y}$ which have the same frame structure also indicated that the CEC is was one of the key factors influencing $\mathrm{Cu}$ adsorption.

\subsection{Analysis of Exchangeable Cations Released at Equilibrium}

An analysis of $\mathrm{Na}, \mathrm{Si}$ and $\mathrm{Al}$ released after the adsorption experiment was conducted. The amount of Na released has been expressed in mmol $\mathrm{kg}^{-1}$ of charge. However, the amount of adsorption expressed in previous explanations was in mmol $\mathrm{kg}^{-1}$ of $\mathrm{Cu}$. Being a divalent ion, the amount of adsorption expressed herein needs to be expressed in moles of positive charge in order to compare with the CEC values. The amount of $\mathrm{Cu}$ adsorption in this study was much lower than the CEC of all the samples. This was thought to be due to the availability of other sources of positive charge which replaced $\mathrm{Na}$ on the surface of the adsorbent. The sources of positive charge were the addition of $\mathrm{H}^{+}$from $\mathrm{HNO}_{3}$ which was used for $\mathrm{pH}$ adjustment, $\mathrm{NH}_{4}{ }^{+}$as a background solution, and also charge from hydroxy-aluminium cations which were released from the zeolite structure. After the adsorption experiment it was noted that there was some amount of Si and $\mathrm{Al}$ released into the supernatant. Altogether, the experiment medium had $\mathrm{Cu}, \mathrm{H}^{+}, \mathrm{NH}_{4}{ }^{+}$, and hydroxy-aluminium cations as sources of positive charge which were available for an exchange with Na present on the surface of the adsorbents hence the high release of $\mathrm{Na}$ at equilibrium in comparison to the amount of $\mathrm{Cu}$ adsorption.

Zeolite A4, faujasite $\mathrm{X}$ and Na-P1 released $\mathrm{Na}$ in quantities that were within the range of the CEC of these samples (CEC values are indicated in Table 1). The amount of Na released for A4, faujasite X, faujasite Y, Na-P1, modernite, montmorillonite and clinoptilolite at the highest initial $\mathrm{Cu}$ concentration was: 6479, 5389, 
1742, 4856, 1495, 436 and $1232 \mathrm{mmol} \cdot \mathrm{kg}^{-1}$ respectively. Zeolites A4 and faujasite were noted to have higher proton selectivity because these samples adsorbed protons, releasing Na into the supernatant even when $\mathrm{Cu}$ adsorption was at its lowest. Additionally, they can adsorb protons even at $\mathrm{pH}$ of 6 to7 according to experiments conducted earlier whose results are not shown in this paper. An analysis of the amount of Na released and the amount of $\mathrm{Cu}$ adsorbed revealed that some amount of Na was released even with very low adsorption of $\mathrm{Cu}$. This was largely due to the available protons in the experiment medium especially $\mathrm{NH}_{4}^{+}$which was added in the highest volume and concentration. Figure 3 is an illustration of this phenomenon. The intercepts in the figure are the amounts of Na replaced by $\mathrm{NH}_{4}^{+}$at the blank runs. The ratio, (Na replaced by $\mathrm{NH}_{4}$ )/CEC, is related to $\mathrm{Na}_{-} \mathrm{NH}_{4}{ }^{+}$exchange selectivity of each sample. A high ratio means high selectivity of the sample toward $\mathrm{NH}_{4}^{+}$.

The figure further indicates that for A4 and Faujasite X, the amount of Na released increased with an increase in adsorption (almost all the available Na was released) while for the rest of the samples, the release of Na decreased with an increase in adsorption (about half of the available Na was released). For A4, faujasite X and $\mathrm{Na}-\mathrm{P} 1$, almost all available $\mathrm{Na}$ is released into the solution while for the rest of the samples; about half of the available $\mathrm{Na}$ is released. There was an almost 1:1 relationship between the amount of Na released and the amount of $\mathrm{Cu}$ adsorbed for $\mathrm{A} 4$, faujasite $\mathrm{X}$ and Na-P1. Since among the samples, proton selectivity is higher for A4, followed by Faujasite $\mathrm{X}, \mathrm{H}^{+}$as well as $\mathrm{NH}_{4}^{+}$were strongly attached to these samples and the weaker $\mathrm{Na}$ was released into solution hence the high release of Na. A study by McBride [32] on Cu interaction with kaolinite reported a similar observation. The study reported that most of the exchangeable Na was released to solution by proton $\left(\mathrm{H}^{+}\right)$exchange even before $\mathrm{Cu}$ became significant in the exchange process, implying that even before adsorption of $\mathrm{Cu}$ had significantly commenced, Na was present in the supernatant.

Although the release of $\mathrm{Na}$ was largely influenced by $\mathrm{NH}_{4}{ }^{+}$, the effect of $\mathrm{H}^{+}$though comparatively minimal was further observed from the change in $\mathrm{pH}$ : an increase in $\mathrm{pH}$ of 0.301 indicates adsorption of half of $\mathrm{H}$, from the definition of $\mathrm{pH}$. This implies that for A4 and faujasite X with greater proton selectivity, nearly $100 \%$ of the proton was adsorbed hence the slightly high rise in $\mathrm{pH}$ compared to the rest of the samples.

On the other hand, it is known that the Si/Al molar ratio of zeolite $\mathrm{A}(=1.00)$ is lower than that of zeolite $\mathrm{X}$ (=1.24). The smaller Si/Al molar ratio in the zeolite framework produces more charge deficiency. Thus, the framework needs more Na to compensate the excess negative charge and more exchangeable Na exist in the zeolite structure. In other words, the amount of exchangeable $\mathrm{Na}$ is inversely proportional to the $\mathrm{Si} / \mathrm{Al}$ molar ratio in the framework of the zeolite structure [19]. This fact also explains the reason behind the high release of $\mathrm{Na}$ from the samples with high CEC and high adsorptive capacity in the current study. A similar observation was reported in a study by Breck on the adsorption of $\mathrm{Cu}$ on zeolite $\mathrm{A}$ and $\mathrm{X}$ [33]. Thus, the amount of exchangeable $\mathrm{Na}$ (or proton since at equilibrium, more $\mathrm{H}^{+}$than $\mathrm{Na}$ existed on the surface of the samples especially A4, Fauja-

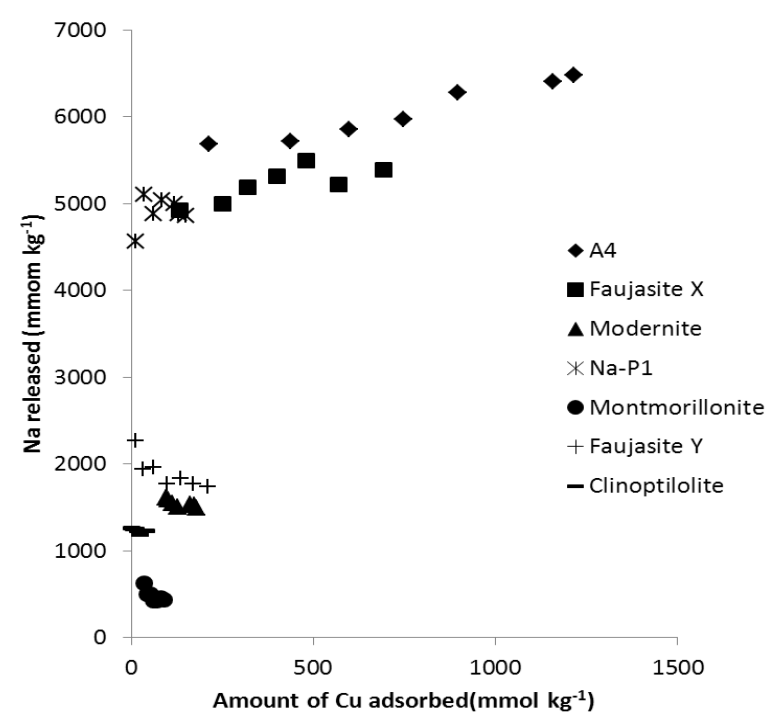

Figure 3. Amount of Na released and the amount of $\mathrm{Cu}$ adsorbed for zeolites A4, faujasite X, faujasite Y, Na-P1, modernite, montmorillonite and clinoptilolite. 
site $\mathrm{X}$ and Na-P1) bonded to zeolites framework plays an important role in the removal performance of heavy metal ions.

With faujasite Y, modernite and clinoptilolite and montmorillonite, the amounts of Na released were below the CEC. This was due to the low selectivity of these samples for $\mathrm{Cu}$ and the other available protons which led to a lower adsorptive capacity as well. This meant that not all the Na available within the samples could be replaced by the $\mathrm{Cu}$ or other protons. In other studies, especially those which were conducted at high $\mathrm{pH}$ of $\geq 6$, it was considered that the mechanism of $\mathrm{Cu}$ removal was based on precipitation of metal hydroxides on the surface of zeolites or inside the pore walls. In the study on heavy metal adsorption on natural zeolite (clinoptilolite) by Filippidis [34], a selectivity sequence of $\mathrm{Fe}^{3+}>\mathrm{Zn}^{2+}>\mathrm{Cu}^{2+}>\mathrm{Mn}^{2+}$ was reported. This sequence however, was not according to the hydration diameters of the heavy metals. The hydration diameters of the samples would give a selectivity sequence of $\mathrm{Cu}^{2+}>\mathrm{Zn}^{2+}>\mathrm{Mn}^{2+}>\mathrm{Fe}^{3+}$ because the hydration radius is smallest for $\mathrm{Cu}$ and highest for $\mathrm{Fe}^{3+}$. It was further reported that the difference in the selectivity series may be an indicator that adsorption is not necessarily the only mechanism responsible for the removal of heavy metal ions from solution; precipitation of the metal hydroxides may have a significant influence in the treatment process by natural zeolite.

Results also showed the presence of $\mathrm{Si}$ and $\mathrm{Al}$ in the supernatant for some of the samples. The leaching of Siand Al-species may be due to the effect of the hydrogen ions on the aluminosilicate framework of the zeolite, which initially causes a rupture of the Al-O bonds and further detachment of Al- and Si-species through hydrolysis reactions [35]. It was however observed that the release of hydroxy-aluminium was higher for all samples compared to that of Si with clinoptilolite and modernite releasing neither Si nor hydroxy-aluminium. Table 3 is a summary of the amount of $\mathrm{Si}$ and $\mathrm{Al}$ released from the sample with the highest initial concentration of $\mathrm{Cu}$. The release of $\mathrm{Al}$ was influenced by the fact that the $\mathrm{H}^{+}$present in the experiment medium initially attacks the negatively charged oxygen atom of the tetrahedral $\mathrm{Al}$ atom, the O-A1 linkage is ruptured and the $\mathrm{A} 1$ atom undergoes some structural rearrangements. The detachment of the A1 atom is a consequence of successive ruptures of the remaining A1-O bonds after a proton attack on the oxygen atom [36].

\subsection{Assessment of the Equilibrium pH}

The $\mathrm{pH}$ of the aqueous solution is an important controlling parameter in the sorption process [37] and metal removal typically increases with increasing $\mathrm{pH}$ values [38]. The $\mathrm{pH}$ may affect the ionization degree of the sorbate and the surface property of the sorbent [39]. Chemically, the solution $\mathrm{pH}$ influences metal speciation. For instance, heavy metal ions may form complexes with inorganic ligands such as $\mathrm{OH}^{-}$. The extent of the complex formation varies with $\mathrm{pH}$, the ionic composition and the particular metal concerned. The exact speciation of a metal has a significant impact on the removal efficiency of the zeolites. The selectivity of metal ion by zeolites is also influenced by the character of the metal complex that predominates at a particular solution $\mathrm{pH}$. Exposure of the zeolite surface to water causes the ionization of surface hydroxyl groups ( $\mathrm{Si} \mathrm{OH}$ and $\mathrm{Al} \mathrm{OH}$ ). The degree of ionization depends on $\mathrm{pH}$, and the acid/base reaction occurring at the hydroxyl groups may results in surface charge development [40].

At low $\mathrm{pH}$, the number of available hydrogen ions is high and $\mathrm{Cu}$ ions have to compete with them for the adsorption sites on the adsorbent surface, leading to lower adsorptive capacity. As $\mathrm{pH}$ gradually increases to around 5 or 6 , adsorptive capacity is enhanced due to the reduction in the amount of $\mathrm{H}^{+}$available which leads to less competition for the available sites of adsorption. At the initial $\mathrm{pH}$ of 5 in this experiment, it was considered that this was the optimum $\mathrm{pH}$ at which adsorption could be possible without much influence from $\mathrm{H}^{+}$as well as controlled precipitation of $\mathrm{Cu}$. The active sites on the adsorbent surface are weakly acidic in nature and with increase in $\mathrm{pH}$, they are gradually deprotonated favoring more and more $\mathrm{Cu}$ uptake. Similar adsorption mechanism has been reported by various authors [41]-[43]. Table 4 is a summary of the equilibrium $\mathrm{pH}$ that was recorded for the samples. Although the initial $\mathrm{pH}$ in current experiments was maintained at 5 , there was variability in the equilibrium $\mathrm{pH}$ with $\mathrm{A} 4$ having a comparatively higher equilibrium $\mathrm{pH}$. There was a slight rise in equilibrium $\mathrm{pH}$ from the initial $\mathrm{pH}$ of 5 for the samples. Although A4 and faujasite had a rise in $\mathrm{pH}$ to a value that was slightly higher than 6 ( 6.22 being the highest for $\mathrm{A} 4$ and 6.19 the highest for faujasite $\mathrm{X}$ ), this rise in $\mathrm{pH}$ was not considered to have affected the adsorption process. Preliminary experiments which were conducted prior to this experiment confirmed that adsorption was constant between $\mathrm{pH} 5$ - 6.5 . 
Table 3. Amounts of Si and $\mathrm{Al}$ released at highest initial concentration of $0.6 \mathrm{mM}$.

\begin{tabular}{|c|c|c|}
\hline Sample & Si released $\left(\mathrm{mmol} \cdot \mathrm{kg}^{-1}\right)$ & Al released $\left(\mathrm{mmol} \cdot \mathrm{kg}^{-1}\right)$ \\
\hline A4 & 21 & 689 \\
\hline Faujasite X & 0.0 & 101 \\
\hline Faujasite Y & 50 & 0.0 \\
\hline Na-P1 & 22 & 1152 \\
\hline Modernite & 0.0 & 0.0 \\
\hline Montmorillonite & 223 & 178 \\
\hline Clinoptilolite & 0.0 & 0.0 \\
\hline
\end{tabular}

Table 4. Changes in the equilibrium $\mathrm{pH}$ after $1 \mathrm{~h}$ of shaking with an initial $\mathrm{pH}$ of 5.

\begin{tabular}{|c|c|c|c|c|c|c|c|}
\hline \multirow{2}{*}{$\begin{array}{l}\text { Initial concentration } \\
\quad\left(\mathrm{mmol} \cdot \mathrm{L}^{-1}\right)\end{array}$} & \multicolumn{7}{|c|}{ Equilibrium $\mathrm{pH}$} \\
\hline & A4 & $\mathrm{X}$ & Na-P1 & MOR & MONT & $\mathrm{Y}$ & CLI \\
\hline 0.05 & 6.22 & 6.19 & 5.53 & 5.18 & 5.32 & 5.13 & 5.27 \\
\hline 0.10 & 6.18 & 6.17 & 5.47 & 5.10 & 5.30 & 5.11 & 5.20 \\
\hline 0.15 & 6.15 & 6.15 & 5.44 & 5.07 & 5.28 & 5.07 & 5.11 \\
\hline 0.20 & 6.02 & 5.99 & 5.43 & 4.98 & 5.25 & 5.03 & 5.11 \\
\hline 0.30 & 5.92 & 5.94 & 5.37 & 4.91 & 5.18 & 4.99 & 5.02 \\
\hline 0.45 & 5.80 & 5.76 & 5.29 & 4.89 & 5.09 & 4.91 & 4.95 \\
\hline 0.60 & 5.75 & 5.68 & 5.22 & 4.85 & 5.07 & 4.86 & 4.89 \\
\hline
\end{tabular}

\section{Conclusion}

The adsorptive selectivity of $\mathrm{Cu}$ on various zeolites and montmorillonite has been studied. From the results of this experiment, it can be concluded $\mathrm{Cu}$ has the highest selectivity toward synthetic zeolites, A4 to be specific, followed by artificial zeolites, then natural zeolites. The selectivity sequence so derived was A4 > faujasite X > modernite $>\mathrm{Na}-\mathrm{P} 1 \approx$ montmorillonite $\approx$ faujasite $\mathrm{Y}>$ clinoptilolite. Further to that, the adsorption of Cu toward zeolites is mostly influenced by the CEC of the zeolite sample in question. The hydration status of $\mathrm{Cu}$ also has the potential of influencing its adsorptivity though CEC plays a much greater role. In some cases, like the case with natural zeolites, precipitation of $\mathrm{Cu}$ also possibly influenced their adsorptive capabilities. The results from this study would be useful in deciding a clean-up option for waste water polluted by heavy metals especially in highly industrialized nations where heavy metal pollution is an issue of serious concern.

\section{References}

[1] Li, N. and Bai, N. (2005) Copper Adsorption on Chitosan-Cellulose Hydrogel Beads: Behaviors and Mechanisms. Separation and Purification Technology, 42, 237-247. http://dx.doi.org/10.1016/j.seppur.2004.08.002

[2] Antunes, W.M., Luna, A.S., Henriques, C.A. and Costa, A.C.A. (2003) An Evaluation of Copper Bio Sorption by a Brown Seaweed under Optimized Conditions. Electronic Journal of Biotechnology, 6, 174-184.

[3] Larous, S., Meniai, A.H. and Lehocine, M.B. (2005) Experimental Study of the Removal of Copper from Aqueous Solutions by Adsorption Using Sawdust. Desalination, 185, 483-490. http://dx.doi.org/10.1016/j.desal.2005.03.090

[4] Rao, M.M., Ramesh, A., Rao, G.P.C. and Seshaiah, K. (2006) Removal of Copper and Cadmium from the Aqueous Solutions by Activated Carbon Derived from Ceiba pentandra Hulls. Journal of Hazardous Materials, 129, 123-129. http://dx.doi.org/10.1016/j.jhazmat.2005.08.018

[5] Wong, K.K., Lee, C.K., Low, K.S. and Haron, M.J. (2003) Removal of Cu and Pb by Tartaric Acid Modified Rice Husk from Aqueous Solutions. Chemosphere, 50, 23-28. http://dx.doi.org/10.1016/S0045-6535(02)00598-2

[6] Quek, S.Y., Wase, D.A.J. and Forster, C.F. (1998) The Use of Sago Waste for the Sorption of Lead and Copper. Water SA, 24, 251-256.

[7] Ozcan, A., Ozcan, A.S., Tunali, S., Akar, T. and Kiran, I. (2005) Determination of the Equilibrium, Kinetic and Thermodynamic Parameters of Adsorption of Copper(II) Ions onto Seed of Capsicum Annuum. Journal of Hazardous Materials, 124, 200-208. http://dx.doi.org/10.1016/j.jhazmat.2005.05.007

[8] Reddy, B.R., Mirghaffari, N. and Gaballah, I. (1997) Removal and Recycling of Copper from Aqueous Solutions Us- 
ing Treated Indian Barks. Resources, Conservation and Recycling, 21, 227-245. http://dx.doi.org/10.1016/S0921-3449(97)00036-0

[9] King, P., Srivinas, P., Prasanna Kumar, Y. and Prasad, V.S.R.K. (2006) Sorption of Copper (II) Ion from Aqueous Solution by Tectona grandis l.f. (Teak Leaves Powder). Journal of Hazardous Materials, 136, 560-566. http://dx.doi.org/10.1016/j.jhazmat.2005.12.032

[10] Sawalha, M.F., Peralta-Videa, J.R., Romero-González, J., Duarte-Gardea, M. and Gardea-Torresdey, J.L. (2007) Thermodynamic and Isotherm Studies of the Biosorption of $\mathrm{Cu}(\mathrm{II}), \mathrm{Pb}(\mathrm{II})$, and $\mathrm{Zn}(\mathrm{II})$ by Leaves of Saltbush (Atriplex canescens). Journal of Chemical Thermodynamics, 39, 488-492. http://dx.doi.org/10.1016/j.jct.2006.07.020

[11] Shukla, S.R. and Pai, R.S. (2005) Adsorption of Cu(II), Ni(II) and Zn(II) on Dye Loaded Groundnut Shells and Sawdust. Separation and Purification Technology, 43, 1-8. http://dx.doi.org/10.1016/j.seppur.2004.09.003

[12] Ho, Y.S., Huang, C.T. and Huang, H.W. (2002) Equilibrium Sorption Isotherm for Metal Ions on Tree Fern. Process Biochemistry, 37, 1421-1430. http://dx.doi.org/10.1016/S0032-9592(02)00036-5

[13] Ngah, W.S.W., Kamari, A., Fatinathan, S. and Ng, P.W. (2006) Adsorption of Chromium from Aqueous Solution Using Chitosan Beads. Adsorption, 12, 249-257. http://dx.doi.org/10.1007/s10450-006-0501-0

[14] Mishra, T. and Tiwari, S.K. (2006) Studies on Sorption Properties of Zeolite Derived from Indian Fly Ash. Journal of Hazardous Materials, 137, 299-303. http://dx.doi.org/10.1016/j.jhazmat.2006.02.004

[15] Peric, J., Trgo, M. and Vukojevic Medvidovic, N. (2004) Removal of Zinc, Copper and Lead by Natural Zeolite-A Comparison of Adsorption Isotherms. Water Research, 38, 1893-1899. http://dx.doi.org/10.1016/j.watres.2003.12.035

[16] Babel, S. and Kurniawam, T.A. (2003) Low-Cost Adsorbents for Heavy Metals Uptake from Contaminated Water: A Review. Journal of Hazardous Materials, 97, 219-243. http://dx.doi.org/10.1016/S0304-3894(02)00263-7

[17] Abollinoa, O., Acetob, M., Malandrinoa, M., Sarzaninia, C. and Mentasti, E. (2003) Adsorption of Heavy Metals on Na-Montmorillonite. Effect of pH and Organic Substances. Water Research, 37, 1619-1627. http://dx.doi.org/10.1016/S0043-1354(02)00524-9

[18] Chen, J., Yiacoumi, S. and Blaydes, T.G. (1996) Equilibrium and Kinetic Studies of Copper Adsorption by Activated Carbon. Separations Technology, 6, 133-146. http://dx.doi.org/10.1016/0956-9618(96)00146-4

[19] Wang, C.F., Li, J.S., Sun, X., Wang, L.J. and Sun, X.Y. (2009) Evaluation of Zeolites Synthesized from Fly Ash as Potential Adsorbents for Wastewater Containing Heavy Metals. Journal of Environmental Sciences, 21, 127-136.

[20] Majdan, M., Pikus, S., Kowalska-Ternes, M., Gładysz-Płaska, A., Staszczuk, P., Fuks, L. and Skrzypek, H. (2003) Equilibrium Study of Selected Divalent $d$-Electron Metals Adsorption on A-Type Zeolite. Journal of Colloid and Interface Science, 262, 321-330. http://dx.doi.org/10.1016/S0021-9797(03)00220-0

[21] Treacy, M.M.J., Higgins, J.B., Von Ballmoos, R. (2001) Collection of Simulated XRD Powder Patterns for Zeolites. 3rd Revised Edition, Elsevier, Amsterdam.

[22] Dixon, J.B. and Weed, S.B. (1989) Minerals in Soil Environments. 2nd Edition, Soil Science Society of America, Madison.

[23] Mering, J. and Brindley, G.W. (1965) X-Ray Diffraction Band Profiles of Montmorillonite-Influence of Hydration and of the Exchangeable Cations. http://www.clays.org/journal/archive/volume\%2015/15-1-51.pdf

[24] McKay, G. (1984) The Adsorption of Basic Dye onto Silica from Aqueous-Solution Solid Diffusion-Model. Chemical Engineering Science, 39, 129-138. http://dx.doi.org/10.1016/0009-2509(84)80138-4

[25] Hui, K.S., Chao, C.Y.H. and Kot, S.C. (2005) Removal of Mixed Heavy Metal Ions in Wastewater by Zeolite 4A and Residual Products from Recycled Coal Fly Ash. Journal of Hazardous Materials, 127, 89-101. http://dx.doi.org/10.1016/j.jhazmat.2005.06.027

[26] Leinonen, H. and Lehto, J. (2001) Purification of Metal Finishing Waste Waters with Zeolites and Activated Carbons. Waste Management \& Research, 19, 45-57. http://dx.doi.org/10.1177/0734242X0101900106

[27] Tansel, B. (2012) Significance of Thermodynamic and Physical Characteristics on Permeation of Ions during Membrane Separation: Hydrated Radius, Hydration Free Energy and Viscous Effects. Separation and Purification Technology, 86, 119-126. http://dx.doi.org/10.1016/j.seppur.2011.10.033

[28] Doula, M.K. and Dimirkou, A. (2008) Use of an Iron-Over Exchanged Clinoptilolite for the Removal of $\mathrm{Cu}^{2+}$ Ions from Heavily Contaminated Drinking Water Samples. Journal of Hazardous Materials, 151, 738-745.

[29] Querol, X., Moreno, N., Umana, J.C., Alastuey, A., Hernandez, E., Lopez-Soler, A. and Plana, F. (2002) Synthesis of Zeolites from Coal Fly Ash: An Overview. International Journal of Coal Geology, 50, 413-423. http://dx.doi.org/10.1016/S0166-5162(02)00124-6

[30] Bogdanov, B., Georgiev, D., Angelova, K. and Yaneva, K. (2009) Natural Zeolites: Clinoptilolite Review. International Science Conference, Stara Zagora, 4-5 June 2009.

[31] Renganathan Sharma, K. (2007) Principles of Mass Transfer. PHI Learning Pvt. Ltd. 
[32] Mcbride, M.B. (1978) Copper (II) Interactions with Kaolinite: Factors Controlling Adsorption. Clays and Clay Minerals, 26, 101-106. http://dx.doi.org/10.1346/CCMN.1978.0260204

[33] Breck, D.W. (1974) Zeolite Molecular Sieves: Structure, Chemistry, and Use. John Wiley \& Sons, New York.

[34] Filippidis, A., Godelitsas, A., Charistos, D., Misaelides, P. and Kassoli-Fournarak, A. (1996) The Chemical Behavior of Natural Zeolites in Aqueous Environments: Interactions between Low-Silica Zeolites and 1M NaCl Solutions of Different Initial pH-Values. Applied Clay Science, 11, 199-209. http://dx.doi.org/10.1016/S0169-1317(96)00025-7

[35] Motsi, T., Rowson, N.A. and Simmons, M.J.H. (2009) Adsorption of Heavy Metals from Acid Mine Drainage by Natural Zeolite. International Journal of Mineral Processing, 92, 42-48. http://dx.doi.org/10.1016/j.minpro.2009.02.005

[36] Takahashi, Y. and Imai, H. (1983) Adsorption of Heavy Metal Cations in Montmorillonite. Soil Science and Plant Nutrition, 29, 111-122.

[37] Elliott, H.A. and Huang, C.P. (1981) Adsorption Characteristics of Some Cu(II) Complexes on Aluminosilicates. Water Research, 15, 849-855. http://dx.doi.org/10.1016/0043-1354(81)90139-1

[38] Huang, C.P. and Ostovic, F.B. (1978) Removal of Cadmium (II) by Activated Carbon Adsorption. Journal of the Environmental Engineering Division, 104, 863-878.

[39] Lin, C.Y. and Yang, D.H. (2002) Removal of Pollutants from Wastewater by Coal Bottom Ash. Journal of Environmental Science and Health, Part A: Toxic/Hazardous Substances and Environmental Engineering, 37, 1509-1522. http://dx.doi.org/10.1081/ESE-120013273

[40] Covarrubias, C., Arriagada, R., Yanez, J., Garcia, R., Angelica, M., Barros, S.D., Arroyo, P. and Sousa-Aguiar, E.F. (2005) Removal of Chromium(III) from Tannery Effluents, Using a System of Packed Columns of Zeolite and Activated Carbon. Journal of Chemical Technology and Biotechnology, 80, 899-908. http://dx.doi.org/10.1002/jctb.1259

[41] Boonamnuayvitaya, V., Chaiya, C., Tanthapanichakoon, W. and Jarudilokkul, S. (2004) Removal of Heavy Metals by Adsorbents Prepared from Pyrolyzed Coffee Residues and Clay. Separation and Purification Technology, 35, 11-22. http://dx.doi.org/10.1016/S1383-5866(03)00110-2

[42] Chu, K.H. (2002) Removal of Copper from Aqueous Solution by Chitosan Prawn Shell: Adsorption Equilibrium and Kinetics. Journal of Hazardous Materials, 90, 77-95. http://dx.doi.org/10.1016/S0304-3894(01)00332-6

[43] Pagnanelli, F., Esposito, A., Toro, L. and Veglio, F. (2003) Metal Speciation and pH Effect on Pb, Cu, Zn and Cd Biosorption onto Sphaerotilus natans: Langmuir-Type Empirical Model. Water Research, 37, 627-633. 